\title{
SUBSTANCE USE AND KNOWLEDGE AMONG ITALIAN HIGH SCHOOL STUDENTS
}

\author{
Lenka Spacilova ${ }^{a}$, Hana Klusonova ${ }^{\mathrm{b}}$, Fabio Petrellic, \\ Carlo Signorelli ${ }^{\mathrm{d}}$, Peter Visnovsky ${ }^{\mathrm{a}}$, Iolanda Grappasonni ${ }^{\mathrm{c}}$
}

a Charles University in Prague, Faculty of Pharmacy in Hradec Kralove, Department of Pharmacology and Toxicology, Heyrovskeho 1203, 50005 Hradec Kralove, Czech Republic

${ }^{b}$ Charles University in Prague, Faculty of Pharmacy in Hradec Kralove, Department of Biological and Medical Sciences, Heyrovskeho 1203, 50005 Hradec Kralove, Czech Republic

${ }^{c}$ University of Camerino, Faculty of Pharmacy, Department of Experimental Medicine and Public Health, Viale E. Betti 3 , 62032 Camerino (MC), Italy

d University of Parma, Department of Public Health, Hygienic Section, Via Volturno 39, 43100 Parma, Italy

e-mail: lenka.spacilova@faf.cuni.cz

Received: November 19, 2008; Accepted: January 17, 2009

Key words: Drug usage/High school students/Italy

Aims: This study was aimed for evaluation of Italian students' attitudes to addictive substances, their knowledge and personal experience, and their awareness about the risks.

Methods: The research was realized among high school students from Marche region in the Central Italy in the year 2006; the study group was randomly chosen from all schools in the region. 4118 appropriately completed questionnaires returned.

The statistic processing was carried out by using chi-square test for two qualitative variables.

\section{RESULTS}

$29.9 \%$ of the students have tried drugs; $36.4 \%$ of the interviewed reckon alcohol, tobacco and antidepressants for drugs. A relationship between the use of licit and illicit addictive substances and a correlation between the use of illicit substances and the use of liquors and tobacco in family was found. The students, who drink frequently, smoke regularly and use drugs, believe that the drugs create dependence only if overused; only a quarter of them classify themselves as drug addicts.

\section{CONCLUSIONS}

The study indicates a lack of information on the drugs among the young people. It emerges that the young people do not sufficiently know the risk of the dependence. A change of the preventive strategies should be considered.

\section{INTRODUCTION}

The study "Substance Use and Knowledge among Italian High School Students" was a questionnaire investigation aimed at evaluation of Italian high school students' attitude to addictive substances, their opinions on the issue, knowledge and personal experience.

The use of licit and illicit substances can noticeably influence the life of young people longing for breaking their own personal limits and give strong emotions. Their quest for being different leads them to the need for sinning $^{1}$. Some authors are holding the theory of drug use progression: from alcoholic beverages to spirits, from tobacco to marihuana and finally to other addictive substances (e.g. heroin) $)^{2-4}$. Early and frequent use of those substances might play a key role together with the above mentioned "progression theory" 5,6 . The latest studies ${ }^{7,8}$ indicate stagnation of a number of problem users unlike the group of occasional experimenters whose number is increasing. Studies in this field point out the presence of a "feeling of invulnerability" developed in teenagers together with low a perception of risks associated with illicit substance use and premature or unprotected $\operatorname{sex}^{9,10}$. The study performed among high school students aged 15-24 years being users of so-called new drugs (synthetic, e.g. XTC) proved that the study persons came from different social environment; they were not marginal and did not develop an anti-social behavior. Many of them did not consider ecstasy, cocaine or amphetamines to be drugs as well as themselves to be drug-dependent ${ }^{11}$. Those substances seem to the users to be extremely safe because they are distributed in non-injectable forms like pills, paper slips or snuff powder which do not produce a risk of transmitting infectious diseases (most frequently viral hepatitis and HIV). Some of those drugs are consumed mainly during weekends when youth needs to relax after "hard" week ${ }^{1}$.

We should take into consideration that alcohol combined with cigarette smoking and illicit substance use becomes more and more popular among young people and 
Table 1. Drug experience.

\begin{tabular}{|l|r|r|r|r|r|r|r|r|}
\hline & \multicolumn{2}{|c|}{ Males } & \multicolumn{2}{c|}{ Females } & \multicolumn{2}{c|}{ not def. sex } & \multicolumn{2}{c|}{ Total } \\
\hline & $\mathrm{n}$. & $\%$ & $\mathrm{n}$. & $\%$ & $\mathrm{n}$. & $\%$ & $\mathrm{n}$. & $\%$ \\
\hline \multicolumn{8}{|c|}{ Have you ever taken drugs? } \\
\hline Yes & 552 & 36.3 & 615 & 25.2 & 64 & 40.0 & 1231 & 29.9 \\
No & 920 & 60.4 & 1779 & 73.0 & 89 & 55.6 & 2788 & 67.7 \\
No answer & 50 & 3.3 & 43 & 1.8 & 5 & 3.2 & 98 & 2.4 \\
\hline \multicolumn{8}{|c|}{} \\
\hline Cannabinoids & 438 & 79.2 & 450 & 73.2 & 51 & 79.7 & 939 & 76.2 \\
Stimulants & 243 & 43.9 & 181 & 29.4 & 28 & 43.8 & 452 & 36.7 \\
Opiates & 54 & 9.8 & 34 & 5.5 & 7 & 10.9 & 95 & 7.7 \\
Hallucinogens & 115 & 20.8 & 48 & 7.8 & 15 & 23.4 & 178 & 15.4 \\
\hline
\end{tabular}

Table 2. Opinions on the meaning of drug.

\begin{tabular}{|c|c|c|c|}
\hline & Definition of drug & $\begin{array}{l}\text { Yes } \\
\mathrm{Nr}\end{array}$ & $\begin{array}{c}\text { Yes } \\
\%\end{array}$ \\
\hline \multirow{4}{*}{$\begin{array}{l}\text { Subjects who have } \\
\text { tried to use drugs } \\
\text { (1231) }\end{array}$} & Substances which alter the psychophysical status of the user & 1075 & 87.3 \\
\hline & Substances taken only by drug addicted & 50 & 4.1 \\
\hline & Substances which drive to drug addiction only if overused & 339 & 27.5 \\
\hline & Other & 85 & 6.9 \\
\hline \multirow{4}{*}{$\begin{array}{l}\text { Subjects who use } \\
\text { drugs, are often } \\
\text { drunk and regu- } \\
\text { larly smoke (314) }\end{array}$} & Substances which alter the psychophysical status of the user & 262 & 83.4 \\
\hline & Substances taken only by drug addicted & 11 & 3.5 \\
\hline & Substances which drive to drug addiction only if overused & 92 & 29.3 \\
\hline & Other & 34 & 10.8 \\
\hline \multirow{4}{*}{$\begin{array}{l}\text { Subjects who } \\
\text { don't take drugs, } \\
\text { aren't often drunk } \\
\text { and don't smoke } \\
(1045)\end{array}$} & Substances which alter the psychophysical status of the user & 980 & 93.8 \\
\hline & Substances taken only by drug addicted & 26 & 2.5 \\
\hline & Substances which drive to drug addiction only if overused & 134 & 12.8 \\
\hline & Other & 23 & 2.2 \\
\hline
\end{tabular}

Table 3. Opinions on drug addiction

(answers of subjects who use drugs, are often drunk and smoke - see Table 2).

\begin{tabular}{|c|c|c|c|c|}
\hline & \multicolumn{4}{|c|}{ "According to you, are the substances you use the real drugs?" } \\
\hline & Yes & No & No answer & Total \\
\hline $\mathrm{Nr}$ & 149 & 125 & 40 & 314 \\
\hline$\%$ & 47,5 & 39,8 & 12,7 & 100,0 \\
\hline
\end{tabular}

Table 4. "Do you think that the ones who take the same substances you said to have taken are drugs addicted?" (answer of 149 subjects who answer "yes" for the previous question - see Table 3).

\begin{tabular}{|c|c|c|c|c|}
\hline & Yes & No & no answer & Total \\
\hline Nr. & 60 & 76 & 13 & 149 \\
\hline$\%$ & 40,3 & 51,0 & 8,7 & 100,0 \\
\hline
\end{tabular}


Table 5. Opinions of the „experienced“ group (314) on drug addiction according to the substances used.

\begin{tabular}{|c|c|c|c|c|c|c|}
\hline & \multicolumn{2}{|c|}{ Usage } & \multicolumn{2}{|c|}{$\begin{array}{c}\text { Do you think } \\
\text { that the substances } \\
\text { you use are the drugs? } \\
\text { YES }\end{array}$} & \multicolumn{2}{|c|}{$\begin{array}{c}\text { Do you think that people } \\
\text { who use the substances } \\
\text { which you have been tried } \\
\text { are the drug users? } \\
\text { NO }\end{array}$} \\
\hline & $\mathrm{Nr}$. & $\%$ & $\mathrm{Nr}$. & $\%$ & $\mathrm{Nr}$. & $\%$ \\
\hline Marijuana & 281 & 89.5 & 140 & 49.8 & 226 & 80.4 \\
\hline Hashish & 219 & 69.7 & 111 & 50.7 & 175 & 79.9 \\
\hline Marijuana + hashish & 210 & 66.9 & 107 & 51.0 & 169 & 80.5 \\
\hline cocaine & 98 & 31.2 & 63 & 64.3 & 73 & 74.5 \\
\hline
\end{tabular}

such combination joints the "better blast" represented by ecstasy ${ }^{12}$.

\section{MATERIAL AND METHODS}

\section{Subjects}

The questionnaire study was performed among high school students from Marche region in the Central Italy; the study group was randomly chosen from all high school in the region. 4118 (55.1\%) appropriately completed questionnaires returned from 7483 which were originally distributed. 1523 (37.0\%) men, 2437 (59.2\%) women and 158 (3.9\%) individuals, who did not state their sex, took part in the survey. Mean age of the respondents was $16.6 \pm 1.5$ years.

\section{Instruments}

The questions presented in the anonymous questionnaire were focused on ascertaining students' knowledge of different addictive substances (alcoholic beverages, tobacco, and illegal drugs), frequency of their use, circumstances under which and environment where the respondents are meeting with illicit substances, motivation leading to the substance use and, finally, basic information sources regarding the issue. In order to increase the comprehensibility, the language of the questionnaire was adapted to responders' mentality, customs and education.

Predominantly closed questions were supplemented with some half-opened and opened questions.

\section{Procedure}

The questionnaire was distributed within school year 2006. The investigators chose the schools with different professional orientation in order to obtain a sample involving all cultural, social and economical levels in the region.

Prior to start of the study the respondents were informed about the aim of the study as well as of importance and usefulness of data provided by them.

The anonymous questionnaire was completed by the responding students themselves with respect to the legislation protecting the privacy - Decreto Legislativo
196/2003 "Codice in materia di protezione dei dati personali" 13 .

\section{Data Analysis}

Windows Access and Microsoft Excel were used for maintaining and processing the data. The statistic processing itself was performed by using chi-square test for two qualitative variables; statistical significance was assessed at the significance level of $p<0.05$. The main goal of statistical analysis was to find and evaluate potential differences of selected parameters between observed respondent groups.

\section{Results}

\section{Socio-demographic factors}

The study group of "Substance Use and Knowledge among Italian High School Students" involved 4118 persons - 1523 (37.0 \%) men, 2437 (59.2 \%) women, $158(3.9 \%)$ individuals did not state their sex. Mean age of the respondents was $16.6 \pm 1.5$ years. Mean age of the men and women was $16.6 \pm 1.6$ years, respectively $16.5 \pm 1.5$ years. Majority of the group was represented by the respondents whose both parents earned Junior School Diploma (fathers: 1515; $36.8 \%$, mothers: 1532; $37.2 \%$ ), followed by parents with High School Diploma (fathers: 1190; $28.9 \%$, mothers: 377; $9.2 \%$ ).

As far as the respondent parents' occupation concerns, $761(18.5 \%)$ fathers worked in public administration, $550(13.4 \%)$ had freelance occupation (trade license), and technical or scientific profession (teacher, physician, lawyer etc.). Majority of the mothers (1459; $35.4 \%)$ were housewives or searching for work. 562 (13.6\%) mothers worked in administration $(562 ; 13.6 \%)$ or had freelance occupation, and technical, scientific or other profession $(496 ; 12.0 \%)$.

\section{Attitudes to and experience with addictive substances \\ 2.1 Results concerning the whole study group \\ 2.1.1 Experience with illicit substances}

1231 students (29.9\%), 552 (36.3\%) men and 615 (25.2\%) women, positively answered the question "Have you tried drugs?" (See the details in the Table 1); more than one half of the respondents $(668 ; 54.2 \%)$ tried 
a drug because they were offered it. The question is whether the students would have felt the need to search actively for the drug if they had not been offered.

Almost one half of the respondents used a drug first at the age of 15 or 16 years, $(260 ; 21.1 \%$ respectively $244 ; 19.8 \%)$. No difference between men and women was observed.

The Table 1 demonstrates cannabis to be the most frequently tried drug (939 students; $76.2 \%$ ). Cannabis is also most frequently used what follows from the answer to the question "What drugs do you use with highest frequency?" (448 persons; $36.4 \%$ ). Cannabinnoid users without specification of drug variant and users combining marijuana and cannabis were more likely men than women $(p<0.05)$. In contrast to this, women preferred using either marijuana or cannabis $(p<0.05)$. Concerning consumption of other drugs, our study confirmed women as using them less than men ( $p<0.05) .64(40.0 \%)$ respondents not stating their sex tried drugs - see the Table 1.

The asked persons identified the following occasions on which they use drugs most frequently: 984 respondents $(79.9 \%)$ mentioned drugs use together with friends, 503 students ( $40.8 \%$ ) during a party, 287 questioned persons $(23.3 \%)$ during a disco and 244 persons (19.8\%) together with partner.

As for the sources providing information on drugs, the respondents mentioned TV (78.8\%), school (77.1\%), public press $(61.7 \%)$, parents $(55.9 \%)$ and friends $(52.5 \%)$; information brochures and religious prints played only a minor role.

Answering the question "What of the following substances do you consider to be drugs?" the respondents frequently qualified as drugs the substances belonging to well-known drugs: 3976 students $(96.5 \%)$ included into the drugs heroin; 3946 students (95.8\%) cocaine; 3778 students (91.7\%) ecstasy; 3513 students $(85.3 \%)$ cannabis; 3383 students (82.1\%) marijuana and 3255 students (79.0 \%) LSD. In contrast, only 1501 students (36.4\%) did this with respect to alcohol, 1440 (35.0\%) cigarettes and $1513(36.7 \%)$ antidepressants. It means that the students consider drugs to be rather illicit substances whereas the licit substances qualify as not possessing an addictive potential.

Almost one third of the respondents - experienced drug users $(339 ; 27.5 \%)$ consider drugs as addictive only in the case of their overuse. This alarming discovery is not accidental; it is a wrong idea which falsely reduces the risk and danger associated with drug abuse. Maybe, it even contributes to that abuse. In contrast to the students without drug experience who realize the risk of psychic and somatic changes caused by drugs, the students who have drug experience do not $(\mathrm{p}<0.05)$. It seems that poor and inappropriate knowledge of the issue can easily lead to experiments with drugs. See the Table 2.

\subsubsection{Experience with licit substances}

The data analysis of using the alcoholic beverages demonstrates that the individuals accustomed to the presence of those beverages within family meals
( $3185 ; 96.6 \%$ ) easier tend to their consumption than the individuals without such experience $(714 ; 17.3 \%)$ $(\mathrm{p}<0.05)$.

Consistent with other studies dealing with the observed issue (2-4), our study confirmed mutual relationship between the use of licit and illicit addictive substances. Only 224 persons (18.2 \%) - experienced drug users have not been yet drunk in contrast to 1991 (69.0\%) respondents without drug experience $(\mathrm{p}<0.05) .325$ experienced users $(26.4 \%)$ drink regularly whereas that number among inexperienced users drops to 58 persons $(2.0 \%)(p<0.05)$. In addition, we found out the correlation between the use of illicit substances and the presence of hard drinks in the family environment $(\mathrm{p}<0.05)$. Only 6 respondents - experienced drug users $(0.5 \%)$ have not met hard drinks in the family in contrast to 1221 (94.6\%) persons admitting the presence of hard drinks at home.

As for student smoking, our results prove that smoking in the family as well as the best friend smoking correlates with tobacco consumption $(p<0.05$ in both cases). 2378 respondents confirmed family smoking. $1718(72.2 \%)$ of them are smokers. Only 660 (27.8 \%) do not smoke at all. In contrast to 1667 (84.4\%) smokers, only 308 ( $15.6 \%$ ) non-smokers are on friendly terms with a smoker. The positive correlation between smoking and use of illicit substances was proved: the experienced drug users smoke more frequently $(1148 ; 93.2 \%)$ than the inexperienced students $(1531 ; 54.9 \%)(\mathrm{p}<0.05)$. Family smoking influences a drug experiments too $(\mathrm{p}<0.05)$. Only $81(6.6 \%)$ of the students - experienced drug users came from non-smoking environment in contrast to $1148(93.3 \%)$ users of illicit substances whose parents were smokers.

\subsection{Results in the study group involving the persons: expe- rienced drug users, frequent drinkers and regular smokers}

The quarter of the respondents - experienced drug users ( 314 from $1231 ; 25.5 \%$ ) drink frequently and smoke regularly. The following results concern just this cohort involving 314 persons ("experienced").

The tendency of trying everything what could be a drug (smoking, alcohol and drugs in the narrow sense of a word) became a part of life style of those young people. No serious reason pressing drug experiments on the young people seems to exist but longing for pleasant feelings (130 persons; $41.5 \%$ ), becoming a member of a collective ( $60 ; 19.0 \%)$, overcoming the boredom (47; $14.9 \%)$, being amused $(179 ; 56.9 \%)$ and, in majority of cases, $(215 ; 68.6 \%)$ tasting new feelings generated by curiosity. Nothing indicates some social problems: Drugs do not represent a goal of students but a mean for its reaching. The moment we realize that the students are passing through psycho-somatic and social development, we can clearly imagine catastrophic consequences resulting from abuse of those substances.

\section{Comparative survey: differences between "the experi- enced" and "the inexperienced" groups}

Another data documenting the origin of the wrong life style of "the experienced" come from comparison of the 
answers produced by those students concerning their drug knowledge with the answers giving by "the inexperienced" (persons who have not got drunk, do not smoke nor use the illicit substances: 1045 students; $25.4 \%$ ). We found a statistically significant difference $(\mathrm{p}<0.05)$ between these two groups concerning their evaluation of the statement "Drugs are substances changing the psycho-somatic status". $262(83.4 \%)$ "experienced" persons consider it to be correct in contrast to 980 (93.8\%) "inexperienced" persons. The incorrect statement "Substances lead to the addiction only if they are overused" is wrongly considered as a correct one by 92 (29.3\%) "experienced" vs. $134(12.8 \%)$ "inexperienced" persons $(\mathrm{p}<0.05)$. See the Table 2.

The respondents from the "experienced" group do not assess themselves to be illicit drugs users. This is based on their answers to the following questions: only 149 (47.5\%) "experienced" persons answered positively to the question "What is your opinion about the substances used by you? Are they drugs with all drug effects?” Only 76 (51.0 \%) respondents who answered positively the above mentioned question answered "yes" also to the next question "Do you think the person to be drug addict if he/she uses the same substances you also declared to use?" No matter that almost a half of the "experienced" group of 314 respondents consider the illicit substances used by them to be real drugs, only a quarter of them $(76 ; 24.2 \%)$ classify themselves as drug addicts. It is interesting that those persons do not see a direct parallel between those phenomena. It demonstrates a certain confusion regarding these two terms: drug and drug addict. Such confusion is not present among members of the second group that does not use drugs, alcohol nor tobacco (see the Tables 3,4 and 5).

\section{DISCUSSION}

Marche region is at the tenth place in Italy for the absolute number of drug related deaths in 2006. But, if the number of deaths is related to every 100.000 inhabitants, the highest values in the last ten years have been recorded in the regions of Umbria, Lazio, Marche and Campania. Marche, therefore, reaches the third place ${ }^{14}$.

These findings correspond to the widespread drug usage among young people. Similarly to the other studies $^{7,15-19}$, our study proved an increasing tendency to the risk behavior among young people. Most adolescents have personal experience with psychoactive substance use, mostly tobacco, alcohol, and marihuana. One of the strongest predictors seems to be the negative peer influence. A clear link between consumption of alcohol, tobacco and illicit substances was found in our study as well as in the other ones ${ }^{20}$.

While in the previous decades the number of problem drug users increased, the current studies prove that the European youth prefers more and more recreational drug use $\mathrm{e}^{7,8,21,22}$. Life-long prevalence of illicit substances use was evidenced in one third of our study group. Our respondents like majority of high school students
- experienced drug users in the European countries ${ }^{22}$ prefer the use of cannabinoids - 939 students (76.2\%; $22.8 \%$ from the whole study group). The value we found among the high school students approaches the life-long prevalence found by ODDA (Observatory on Drugs and Drug Addiction, Italy) in national survey among young adults $^{21}$. This confirms that experimental use of cannabis prevails among young people and decreases with increasing age ${ }^{21,23}$. A relatively small number of the experienced respondents - 95 persons $(7.7 \% ; 2.3 \%$ from the whole group) abused so dangerous substances like heroin.

According to the Italian Annual Report the life-long prevalence of cocaine use among the whole Italian population is $6.3 \%$. Recently, in the region Marche, $4-5 \%$ of 15-19 years aged students admitted to the cocaine experience $^{21}$. The study that proved the presence of the cocaine metabolites in the water of some main European rivers (Po, Rhine and Thames) in concentrations higher than those calculated with respect to the previous epidemiological studies ${ }^{24}$, seems to demonstrate that not all actual users admitted to cocaine use. This is confirmed by our results demonstrating surprising number of 452 "experienced" students ( $36.7 \%$; $11.0 \%$ of the whole study group) who tried stimulating agents (e.g. cocaine).

\section{CONCLUSIONS}

Our study reflects the attitudes to drug issue of certain young people with their unique opinions on life and attitudes to it, determined by actual life conditions, their age and social background. Despite potential methodological differences regarding the data collection, similar findings obtained with answers to similarly formulated questions as used in other studies ${ }^{21,22}$ seem to support validity of our results.

Although we can not generalize the results of our study, the project revealed the facts which should not be put aside. The use of illicit substances, including alcoholism and nicotinism, arise from wrong opinions and attitudes formed by the current young people in a premature way. This is why the correct upbringing and earning the positive life experience are enormously important. Part of our study group involving the students - experienced drug users held the opinion that drugs lead to the addiction only if they are overused. Although the students realize their abusing the drugs, they do not consider themselves to be addicts. Their wrong interpretation is surprising if we consider intensity of various information and preventive campaigns focused on those persons. However, there is a question of effectiveness of the campaigns. Our study as well as that performed by Planchere ${ }^{25}$ suggested a lack of information on drugs among the young people. Respecting this finding it seems desirable to change preventive programs in order to improve their effectiveness. The request for the improvement is also based on the fact that the young people identify the public communication means, school, family and friends as main information source about drugs. Information brochures are mentioned as last sources. 
Preventive programs should focus on various goals like improvement of knowledge about harmful effects of psychotropic substances. However, above all the programs should help the young people to accept the responsibility for their social, psychic, emotional and somatic health. They should help them to make an intentional choice of correct life style. This young man might get "an agent of prevention" within interpersonal relationships. He/she can become an example for his/her friends, siblings and other individuals occasionally or regularly misusing the drugs. A privileged place of prevention appears to be the school because of its fundamental role in the process of development of personality. It possesses the advantage of being most widened, organized system that involves all age categories. The programs of drug prevention and general health education programs should form an educational program penetrating into various school subjects.

\section{ACKNOWLEDGEMENTS}

The authors would like to acknowledge to the persons who took part in the survey and to Luca Massei who has elaborated the data.

\section{REFERENCES}

1. Orlandini D, Nardelli R, Cavallin V, Potente R. Adolescenza, alcool, droghe e comportamenti a rischio [Adolescence, alcohol, drugs and risk behaviours]. In: Cibin M, Orlandini D, Rampazzo L, editors. Alcologia, Prevenzione, Progettualità regionale [Alcoholism, Prevencion, Regional Projects]. Venice: La Garangola Ed; 2000.

2. Fergusson DM, Horwood LJ. Does cannabis use encourage other forms of illicit drug use? Addiction 2000; 95:505-520.

3. Grant JD, Scherrer JF, Lynskey MT, Lyons MJ, Eisen SA, Tsuang MT et al. Adolescent alcohol use is a risk factor for adult alcohol and drug dependence: evidence from a twin design. Psychol Med 2006; 36:109-118.

4. Lessem JM, Hopfer CJ, Haberstick BC, Timberlake D, Ehringer MA, Smolen A et al. Relationship between adolescent marijuana use and young adult illicit drug use. Behav Genet 2006; 36:498-506.

5. Kandel D, Yamaguchi K. From beer to crack: developmental patterns of drug involvement. Am J Public Health 1993; 83:851-855.

6. Wagner FA, Anthony JC. Into the world of illegal drug use: exposure opportunity and other mechanisms linking the use of alcohol, tobacco, marijuana, and cocaine. Am J Epidemiol 2002; 155:918925.

7. EMCDDA. Annual Report 2006: the State of the Drugs Problem in Europe. Luxembourg: Office for Official Publications of the European Communities; 2007.

8. Mravcik V et al. Annual Report: the Czech Republic - 2005 Drug Situation. Prague: Office of the Government of the Czech Republic; 2006.
9. Paglia A, Room, A. Preventing Substance abuse among youth: literature review and reccomendations. J Prim Prev 1993; 20:433-442.

10. Quadrel MJ, Fischhoff B, Davis W. Adolescent (in)vulnerability. Am Psychol 1993; 48:102-116.

11. Beck J, Rosenbaum M. The pursuit of ecstasy. New York: State University of New York Press, 1993.

12. Hawkins JD, Catalano RF, Miller JY. Risk and protective factors for alcohol and other drug problems in adolescence and early adulthood: implications for substance abuse prevention. Psychol Bull 1992; 112:64-105.

13. Decreto legislativo 30 giugno 2003, n. 196 - Codice in materia di protezione dei dati personali. Vigenza 27 febbraio $2004-$ Consolidato con la legge 26 febbraio 2004, n. 45 di conversione con modifiche dell'art. 3 del d.1. 24 dicembre 2003, n. 354. (GU n. 174 del 29-7-2003 - Suppl. Ord. n. 123 - Testo in vigore dal 1-12004).

14. Annuale 2006 DCSA. Parte Quinta [Annual Report 2006 DCSA. Fifth Part]. Rome: Ministry of Interior; 2007: Available from www. governo.it/GovernoInforma/Dossier/droga_relazione2006/documenti/ann_partequinta.pdf. Accessed June 29, 2007.

15. Golub A, Johnson BD, Dunlap E. The growth in marijuana use among American youths during the 1990s and the extent of blunt smoking. J Ethn Subst Abuse 2005; 4:1-21.

16. Lucas AC, Parente RC, Picanco NS, Conceição DA, Costa KR, Magalhães IR et al. [Use of psychoactive drugs by health sciences undergraduate students at the Federal University in Amazonas, Brazil]. Cad Saude Publica 2006 ;22:663-671.

17. Malatestinic D, Micovic V, Kendel G, Baricev-Novakovic Z. Assessment of psychological and social factors in adolescents risk behavior: questionnaire study. Croat Med J 2005; 46:81-87.

18. Sutherland I, Shepherd JP. The prevalence of alcohol, cigarette and illicit drug use in a stratified sample of English adolescents. Addiction 2001; 96:637-640.

19. Zaborskis A, Sumskas L, Maser M, Pudule I. Trends in drinking habits among adolescents in the Baltic countries over the period of transition: HBSC survey results, 1993-2002. BMC Public Health 2006; 6:67.

20. Ljubotina D, Galic J, Jukic V. Prevalence and risk factors of substance use among urban adolescents: questionnaire study. Croat Med J 2004; 45:88-98.

21. EMCDDA. 2004 National Report to the EMCDDA by the National Reitox Focal Point. "Italy". New Developments, trends and in-depth information on selected issues. Luxembourg: Office for Official Publications of the European Communities; 2005. Available from http://www.emcdda.europa.eu/ Accessed November 27, 2005.

22. Hibel B, Andersson B, Bjarnason T, Ahlstroem S, et al. The ESPAD Report 2003. Alcohol and Other Drug Use among Students in 35 European Countries. Stockholm: Swedish Council for Information on Alcohol and Other Drugs; 2004.

23. Copeland J, Gerber S, Dillon P, Swift W. Cannabis. Answer to Your Questions. Canberra: Australian National Council on Drugs; 2006.

24. Zuccato E, Chiabrando C, Castiglioni S, Calamari D, Bagnati R, Schiarea $\mathrm{S}$ et al. Cocaine in surface waters: a new evidence-based tool to monitor community drug abuse. Environ Health 2005; 4:14.

25. Plancherel B, Bolognini M, Stephan P, Laget J, Chinet L, Bernard $\mathrm{M}$ et al. Adolescents' beliefs about marijuana use: a comparison of regular users, past users and never/occasional users. J Drug Educ 2005; 35:131-146. 